Medical Principles and Practice
Med Princ Pract 2012;21:467-471

DOI: $\underline{10.1159 / 000337437}$
Received: July 7, 2011

Accepted: February 23, 2012

Published online: March 31, 2012

\title{
Risk Factors in Patients with Hereditary Gallstones in Chinese Pedigrees
}

\author{
Yunfeng Cui Zhonglian Li Erpeng Zhao Naiqiang Cui \\ Department of Surgery, Tianjin Nankai Hospital, Nankai Clinical School of Medicine, Tianjin Medical University, \\ Tianjin, China
}

\section{Key Words}

Risk factor $\cdot$ Hereditary $\cdot$ Chinese pedigrees $\cdot$ Metabolic

syndrome $\cdot$ First-degree relative

\begin{abstract}
Objective: We aimed to define the risk factors and to evaluate the impact of family background on the prevalence of gallstones in China. Subjects and Methods: Thirty-eight gallstone pedigrees were collected and a case-control study was conducted. This study consisted of 272 first-degree relatives and 201 non-first-degree relatives of index patients. The participants completed a questionnaire and underwent physical and ultrasonographic examinations. The risk factors examined included age, sex, body mass index (BMI), smoking status, alcohol consumption, pregnancy, fat content in dietary meat, history of gastrointestinal surgery, hypertension, hyperlipidemia, fatty liver, coronary heart disease and diabetes. Results: The prevalence of gallstones in first-degree and non-first-degree relatives of index patients was 38.2 and $10.9 \%$, respectively. Age, pregnancy and BMI significantly differed between cases and controls $(p<0.05)$. The relative risks were: consumption of meat with a high fat content 1.4 (95\% Cl 1.1-1.8); hyperlipidemia 2.4 (95\% Cl 1.3-4.6); diabetes 1.9 (95\% Cl 1.1-3.2); fatty liver 4.9 (95\% Cl 1.0-24); coronary heart disease 2.5 (95\% Cl 1.7-3.9). Conclusion: Data showed that age, overweight, more consumption of high-fat
\end{abstract}

\section{KARGER}

Fax +4161306 1234

E-Mail karger@karger.ch

www.karger.com
(C) 2012 S. Karger AG, Basel

$1011-7571 / 12 / 0215-0467 \$ 38.00 / 0$

Accessible online at:

www.karger.com/mpp food, high frequency of pregnancy, fatty liver, hyperlipidemia, coronary heart disease and diabetes could increase the risk of gallstones in the first-degree relatives of index patients.

Copyright $\odot 2012$ S. Karger AG, Basel

\section{Introduction}

Gallstones are a major public health problem in all developed countries. Gallstones are also the most common disease of the biliary system and in most cases are asymptomatic [1]. Gallbladder disease today is a common problem: 20 to 25 million Americans harbor gallstones, representing $10-15 \%$ of the adult population [2]. Recent studies indicate a varying prevalence of gallstones with several risk factors in different study populations [3-8]. Ates et al. [9] reported that there was a higher prevalence of gallstone disease in chronic myelocytic leukemia patients than in healthy controls. Therefore, strategies to reduce the prevalence of gallstones are vital.

Many previous studies [10, 11] have shown that gallstone formation is multifactorial, including constitutional and environmental factors. Some factors, such as diet, activity, rapid weight loss and obesity, are modifiable, whereas others (e.g. age, female gender, genetics and ethnicity) cannot change [10]. In Taiwan, age $>60$ years and 
diabetes mellitus were risk factors for gallstones among older persons [11].

Familial and epidemiologic studies demonstrate that genetic susceptibility is important in the formation of gallstones [12]. Occurrence within families can be a product of genetic and shared environmental factors. A better understanding of the risk factors on a familial background may help us to identify patients with gallstones and reduce the risk of gallstones in some patients. Therefore, we conducted a case-control study to identify risk factors associated with gallstones in pedigrees.

\section{Subjects and Methods}

\section{Subjects}

Thirty-eight gallstone pedigrees were collected. The criterion of familial background was such that there were not less than two patients who were in different generations of consanguinity in one family. This study consisted of 473 participants enrolled between July 2007 and July 2009 at the Department of Surgery, Tianjin Nankai Hospital, and they were distributed in 38 gallstone pedigrees. Among these 473 participants, 272 were the first-degree relatives of index gallstone patients and 201 were non-firstdegree relatives. The 272 first-degree relatives were divided into the case participants, comprising 104 participants with a diagnosis of gallstone, and the control participants, comprising 168 subjects without gallstone. Approval for the study by the Ethics Committee of Tianjin Nankai Hospital and informed consent from all participants were obtained.

\section{Data Collection}

Each participant was interviewed in person in the Outpatient Department. Clinical and ultrasonographic examinations were performed and interviews were conducted by trained interviewer. Participants with gallstones were examined by ultrasonography to confirm the diagnosis or had a confirmed cholecystectomy history because of gallstone.

During the interview, all participants were asked to provide information about age, sex, past medical history and other demographic data. They were also asked to describe their food preferences, such as the fat content of the meat they consumed. Drinkers were classified according to the duration of alcohol consumption. Smokers were classified according to the duration of cigarette smoking. Body mass index (BMI, $\left.\mathrm{kg} / \mathrm{m}^{2}\right)$ was used as a measurement of obesity. Normal weight was defined as a BMI $<25 \mathrm{~kg} / \mathrm{m}^{2}$, overweight as $\geq 25 \mathrm{~kg} / \mathrm{m}^{2}$. The presence or absence of hyperlipidemia, fatty liver, hypertension, coronary heart disease and diabetes mellitus was obtained from the medical records. Participants were asked about the date of and age at diagnosis of these diseases.

\section{Statistical Analysis}

Data were analyzed by using SPSS 16 (version 20.0.0). Comparison between demographic characteristics of participants was performed using $\chi^{2}$ test or Fisher's exact test. Multivariate analysis by unconditional binary logistic regression was used to determine relative risk and 95\% CI for risk factors of gallstones.

\section{Results}

The prevalence of gallstones was significantly higher in the 272 first-degree relatives of index patient than in the 201 non-first-degree relatives (38.2 vs. $10.9 \%$, p = 0.001). The incidence of gallstones for parents, siblings and offsprings of index patient was 39.2, 44.6 and 18.4\%, respectively.

The results of univariate analysis of the participants are shown in table 1 . The prevalence of gallstones in females and males was 42.8 and $31.9 \%$, and there was no significant difference in sex between cases and controls $(\mathrm{p}>0.05)$. The prevalence of the three age groups was 22.2, 38.0 and 52.8\%, respectively. Most cases had a BMI $\geq 25 \mathrm{~kg} / \mathrm{m}^{2}$, while most controls had a BMI $<25 \mathrm{~kg} / \mathrm{m}^{2}$. The average BMI among the case participants was 25.35 \pm 3.12 , which was significantly higher than that of the control participants $(19.85 \pm 5.01)$. Age and BMI significantly differed between cases and controls $(\mathrm{p}<0.05)$. History of smoking, alcohol consumption, gastrointestinal operation and hypertension were not associated with the prevalence of gallstones $(p>0.05)$. However, fat content in dietary meat, hyperlipidemia, diabetes mellitus and coronary heart disease showed significant differences between cases and controls $(\mathrm{p}<0.05)$. As compared to participants without pregnancy, those with $1-2$ had a relative risk of 1.2 (95\% CI 1.1-1.3) and those with $\geq 3$ had a relative risk of 2.4 (95\% CI 1.4-4.2).

The results of multivariate analysis adjusted for age and sex by using unconditional multiple logistic regression are shown in table 2. History of smoking, alcohol consumption, gastrointestinal operation and hypertension were not associated with gallstones, as with univariate analysis. Participants with a BMI $\geq 25 \mathrm{~kg} / \mathrm{m}^{2}$ had a higher risk of gallstone disease compared to those with a BMI $<25 \mathrm{~kg} / \mathrm{m}^{2}$. Fat content in dietary meat was also positively correlated with a higher prevalence of gallstones. Hyperlipidemia, diabetes, coronary heart disease and fatty liver were all positive risk factors for gallstone disease in the logistic model. These findings in logistic analysis are closely consistent with the results of univariate analysis.

\section{Discussion}

Our finding that the prevalence of gallstones was significantly higher in first-degree relatives than in nonfirst-degree relatives of index patients confirmed the notion that genetic factors play a very important role in the 
Table 1. Demographic characteristics of cases and controls in first-degree relatives

\begin{tabular}{|c|c|c|c|}
\hline Characteristics & $\begin{array}{l}\text { Cases } \\
(\%)\end{array}$ & $\begin{array}{l}\text { Controls } \\
\text { (\%) }\end{array}$ & $\begin{array}{l}\mathrm{p} \\
\text { value }\end{array}$ \\
\hline Number of participants & 104 & 168 & \\
\hline Sex & & & 0.0681 \\
\hline Male & $36(31.9)$ & 77 (68.1) & \\
\hline Female & $68(42.8)$ & $91(57.2)$ & \\
\hline Age & & & 0.0013 \\
\hline$<35$ & $14(22.2)$ & $49(77.8)$ & \\
\hline $35-60$ & $52(38.0)$ & $85(62.0)$ & \\
\hline$>60$ & $38(52.8)$ & $34(47.2)$ & \\
\hline BMI & & & 0.009 \\
\hline$<25 \mathrm{~kg} / \mathrm{m}^{2}$ & $45(31.0)$ & $100(69.0)$ & \\
\hline$\geq 25 \mathrm{~kg} / \mathrm{m}^{2}$ & $59(46.5)$ & $68(53.5)$ & \\
\hline Period of alcohol consumption & & & 0.6312 \\
\hline Nondrinker & $50(38.5)$ & $80(61.5)$ & \\
\hline$<5$ years & $36(42.4)$ & $49(57.6)$ & \\
\hline $5-10$ years & $11(30.6)$ & $25(59.4)$ & \\
\hline$>10$ years & $7(33.3)$ & $14(66.7)$ & \\
\hline Period of cigarette consumption & & & 0.3619 \\
\hline Nonsmoker & $70(35.5)$ & $127(64.5)$ & \\
\hline$<5$ years & $8(53.3)$ & $7(46.7)$ & \\
\hline $5-10$ years & $13(39.4)$ & $20(60.6)$ & \\
\hline$>10$ years & $13(48.1)$ & $14(51.9)$ & \\
\hline Fat content in dietary meat & & & 0.0373 \\
\hline Low & $51(32.9)$ & $104(67.1)$ & \\
\hline High & $53(45.3)$ & $64(54.7)$ & \\
\hline Number of pregnancies & & & 0.0052 \\
\hline 0 & $2(11.1)$ & $16(88.9)$ & \\
\hline $1-2$ & $52(44.1)$ & $66(55.9)$ & \\
\hline$\geq 3$ & $14(60.9)$ & $9(39.1)$ & \\
\hline History of GI operation & & & 0.1428 \\
\hline Yes & $7(58.3)$ & $5(41.7)$ & \\
\hline No & $97(37.3)$ & $163(62.7)$ & \\
\hline Hypertension & & & 0.5419 \\
\hline Yes & $46(40.4)$ & $68(59.6)$ & \\
\hline No & $58(36.7)$ & $100(63.3)$ & \\
\hline Hyperlipidemia & & & 0.0045 \\
\hline Yes & $21(60.0)$ & $14(40.0)$ & \\
\hline No & $83(35.0)$ & $154(65.0)$ & \\
\hline Diabetes mellitus & & & 0.0249 \\
\hline Yes & $23(53.5)$ & $20(46.5)$ & \\
\hline No & $81(35.4)$ & $148(64.6)$ & \\
\hline Fatty liver & & & 0.0275 \\
\hline Yes & $6(75.0)$ & $2(25.0)$ & \\
\hline No & $96(36.6)$ & $166(63.4)$ & \\
\hline Coronary heart disease & & & 0.001 \\
\hline Yes & $41(61.2)$ & $26(38.8)$ & \\
\hline No & $63(30.7)$ & $142(69.3)$ & \\
\hline
\end{tabular}

Table 2. Risk factors associated with gallstone disease in firstdegree relatives and adjusted for age and sex by unconditional binary logistic regression

\begin{tabular}{llll}
\hline Factor & Comparison & $\begin{array}{l}\text { Relative } \\
\text { risk }\end{array}$ & 95\% CI \\
\hline BMI & $\geq 25$ vs. $<25$ & 1.6 & $1.1-2.0$ \\
Fat content in dietary meat & high vs. low & 1.4 & $1.1-1.8$ \\
Hyperlipidemia & yes vs. no & 2.4 & $1.3-4.6$ \\
Diabetes mellitus & yes vs. no & 1.9 & $1.1-3.2$ \\
Fatty liver & yes vs. no & 4.9 & $1.0-24$ \\
Coronary heart disease & yes vs. no & 2.5 & $1.7-3.9$ \\
\hline
\end{tabular}

pathogenesis of gallstones, and other reports that gallstone disease had an increased frequency in family clusters (about 5 times more common in families of affected persons) [13]. Systemic genome-wide scans in mice from experimental crosses of inbred mouse strains have mapped the 'Lith' loci that increase gallstone susceptibility $[14,15]$. A growing number of genetic variants in these genes have been linked to human gallstone disease [16]. Our previous findings indicated that SCP2 might be one of the genetic factors contributing to cholesterol gallstone formation [17].

The findings in our study confirmed and expanded those of some previous studies that investigated the risk factors of gallstones under un-family background. Female gender was reported to be one of the most important risk factors for gallstone disease, women being almost twice as likely as men to form gallstones [1]. Our results showed that the incidence of gallstones in females was higher than that in males, however there was no statistical significance $(\mathrm{p}>0.05)$. Pregnancy was related to a higher risk of gallstone disease, which was consistent with the findings of Scragg et al. [18]. A probable explanation is that female sex hormones adversely influence hepatic bile secretion and gallbladder function. Estrogens can increase cholesterol secretion and diminish bile salt secretion. Similarly, progestin functions by reducing bile salt secretion and impairing gallbladder emptying, leading to bile stasis. Gallstone disease is usually rare in neonates and young children, but there is evidence that the incidence of gallstones progressively increases with age. Our finding that age is a risk factor for gallstones confirmed the findings of Maurer et al. [19] in MexicanAmericans, Cuban-Americans and mainland Puerto Ricans, and of Chen et al. [11] in senior citizens of Taiwan. We also found that BMI was positively correlated with the 
onset of gallstones, and the possible reason was that obesity could lead to increased cholesterol synthesis and secretion of cholesterol into bile; our results confirmed the previous study [20]. We found that neither the period of alcohol consumption nor history of smoking was a risk factor of gallstones, which contradicts previous reports $[19,21]$. The possible reason is unclear, maybe this is because they are not direct causal factors for gallstones.

Our results showed that more consumption of high-fat foods was tightly associated with a higher risk of gallstones. Misciagna et al. [22] also observed that more highfat diet could increase the risk of gallstones. Genetic variations, especially in genes controlling cholesterol metabolism, presumably underscore why some persons are subject to dietary changes and easily develop cholesterol gallstones [23]. Although dietary factors appear to be associated with gallstones, the link between diet and gallstone formation may not be straightforward. It is generally accepted that gallstone formation is caused by genetic factors along with multiple environmental factors, and interactions between related genes and dietary factors play an important role in the pathogenesis of gallstone formation. Based on our findings, we think that persons with a family background are more susceptible to high-fat diet.

In this study, we found that some diseases, such as fatty liver, hyperlipidemia, coronary heart disease and diabetes, were closely associated with gallstones, which was consistent with some previous studies [24], but it was not found that hypertension and former gastrointestinal operation could increase the risk of gallstone disease. These four positive risk factors are all related to abnormal lipid metabolism, so this indicates that lipid disorder may be the core part in the pathogenesis of familial gallstone disease.

All diseases which were risk factors for familial gallstones were involved in metabolic problems. The metabolic syndrome was usually defined as a specific body phenotype (abdominal obesity), insulin resistance (type 2 diabetes mellitus) and dyslipidemia, all risks for cardiovascular disease. According to recent reports, all these diseases had hereditary features and family background. It is probable that familial gallstone disease shares some similar genetic backgrounds with these diseases, and some genes targeted to these hereditary disorders might take some effects in the formation of familial gallstones. Therefore, much more research work should be done to elucidate the possible genetic mechanisms in the future.

\section{Conclusion}

Our findings indicated that age, overweight, more consumption of high-fat food, high frequency of pregnancy, fatty liver, hyperlipidemia, coronary heart disease and diabetes increased the risk of gallstone disease in the first-degree relatives of index patients.

\section{Acknowledgement}

This study was supported by grants from the National Natural Science Foundation of China, No. 30600602, and the Natural Science Foundation of Tianjin, No. 08JCYBJC08700.

\section{References}

1 Lirussi F, Nassuato G, Passera D, Toso S, Zalunardo B, Monica F, Virgilio C, Frasson F, Okolicsanyi L: Gallstone disease in an elderly population: the Silea study. Eur J Gastroenterol Hepatol 1999;11:485-491.

12 Shaffer EA: Gallstone disease: epidemiology of gallbladder stone disease. Best Pract Res Clin Gastroenterol 2006;20:981-996.

$\checkmark 3$ De Santis A, Attili AF, Ginanni Corradini S, Scafato E, Cantagalli A, De Luca C, Pinto G, Lisi D, Capocaccia L: Gallstones and diabetes: a case-control study in a free-living population sample. Hepatology 1997;25:787790

4 Chung YJ, Park YD, Lee HC, et al: Prevalence and risk factors of gallstones in a general health screened population (in Korean). Korean J Med 2007;72:480-490.
5 Sasazuki S, Kono S, Todoroki I, et al: Impaired glucose tolerance, diabetes mellitus, and gallstone disease: an extended study of male self-defense officials in Japan. Eur J Epidemiol 1999;15:245-251.

$\checkmark 6$ Liu CM, Tung TH, Liu JH, Lee WL, Chou P: A community based epidemiologic study on gallstone disease among type 2 diabetics in Kinmen, Taiwan. Dig Dis 2004;22:87-91.

7 Everhart JE, Khare M, Hill M, Maurer KR: Prevalence and ethnic differences in gallbladder disease in the United States. Gastroenterology 1999;117:632-639.

8 Rasromani K, Jamsheer N, Mohammed AM, Al Mahroos S, Mannan Khan I, Kamath KM: Prevalence of cholelithiasis in sickle cell disease. Med Princ Pract 1990/1991;2:182-184.
9 Ates F, Erkurt MA, Karincaoglu M, Aladag M, Aydogdu I: Prevalence of gallstones in patients with chronic myelocytic leukemia. Med Princ Pract 2009;18:175-179.

10 Stinton LM, Myers RP, Shaffer EA: Epidemiology of gallstones. Gastroenterol Clin North Am 2010;39:157-169.

11 Chen CY, Lu CL, Lee PC, Wang SS, Chang FY, Lee SD: The risk factors for gallstone disease among senior citizens: an Oriental study. Hepatogastroenterology 1999;46:1607-1612.

12 Lammert F, Miquel JF: Gallstone disease: from genes to evidence-based therapy. J Hepatol 2008;48(suppl 1):S124-S135.

13 Sarin SK, Negi VS, Dewan R, Sasan S, Saraya A: High familial prevalence of gallstones in the first-degree relatives of gallstone patients. Hepatology 1995;22:138-141. 
14 Lammert F, Carey MC, Paigen B: Chromosomal organization of candidate genes involved in cholesterol gallstone formation: a murine gallstone map. Gastroenterology 2001;120:221-238.

15 Wang DQ, Afdhal NH: Genetic analysis of cholesterol gallstone formation: searching for Lith (gallstone) genes. Curr Gastroenterol Rep 2004;6:140-150.

16 Lyons MA, Wittenburg H: Cholesterol gallstone susceptibility loci: a mouse map, candidate gene evaluation, and guide to human LITH genes. Gastroenterology 2006;131: 1943-1970.

-17 Cui Y, Li Z, Zhao E, Jia Y, Li D, Zhang J, Cui $\mathrm{N}$ : Overexpression of sterol carrier protein 2 in patients with hereditary cholesterol gallstones. BMC Gastroenterol 2011;11:10.
18 Scragg RK, McMichael AJ, Seamark RF: Oral contraceptives, pregnancy, and endogenous oestrogen in gallstone disease - a case-control study. Br Med J (Clin Res Ed) 1984;288: 1795-1799.

19 Maurer KR, Everhart JE, Ezzati TM, Johannes RS, Knowler WC, Larson DL, Sanders R, Shawker TH, Roth HP: Prevalence of gallstone disease in Hispanic populations in the United States. Gastroenterology 1989;96: 487-492.

20 Maclure KM, Hayes KC, Colditz GA, Stampfer MJ, Speizer FE, Willett WC: Weight, diet, and the risk of symptomatic gallstones in middle-aged women. N Engl J Med 1989;321: 563-569.
21 Jorgensen T: Gall stones in a Danish population. Relation to weight, physical activity, smoking, coffee consumption, and diabetes mellitus. Gut 1989;30:528-534.

22 Misciagna G, Centonze S, Leoci C, Guerra V, Cisternino AM, Ceo R, Trevisan M: Diet, physical activity, and gallstones - a population-based, case-control study in southern Italy. Am J Clin Nutr 1999;69:120-126.

23 Rudkowska I, Jones PJ: Polymorphisms in ABCG5/G8 transporters linked to hypercholesterolemia and gallstone disease. Nutr Rev 2008;66:343-348.

24 Loria P, Lonardo A, Lombardini S, Carulli L, Verrone A, Ganazzi D, Rudilosso A, D’Amico R, Bertolotti M, Carulli N: Gallstone disease in non-alcoholic fatty liver: prevalence and associated factors. J Gastroenterol Hepatol 2005;20:1176-1184. 